\title{
A Study On Effects Of The Most Commonly Used Chemotherapeutic Drugs On Haematological Parametres.
}

\author{
"PV.Akshaya ${ }^{1}$, Mounika $\mathrm{R}^{1}$, Reddy $\mathrm{SV}^{1}$ chaudhary $\mathrm{GP}^{1}$, Srinivasan. $\mathrm{R}^{2}$, \\ Sharma $S^{2}$, \\ Department of Pharmacy Practice, PES College of Pharmacy, Hanumanthnagar, Bangalore - 560 050, \\ Karnataka, India \\ Corresponding Author: PV.Akshaya
}

\begin{abstract}
Cancer is a group of more than hundred diseases that are characterized by uncontrolled cellular growth, local tissue invasion, and distant metastasis. To treat the cancer there are many types of treatments that includes Surgery, Radiation therapy, Chemotherapy.Data collection form was designed and piloted to collect, document and analyse the data. The data collection form had provision for collecting key information like demographics (UHID, age, gender, weight), past medical history, present diagnosis, and laboratory investigations, medications their dose and duration, frequency, clinical progress and assessed for adverse drug reaction. Chemotherapy induced haematological disorders is a common problem in cancer patients who are treated with the myelosuppression chemotherapy, many patients with chemotherapy induced haematological disorders tend to be under treated clinically. Untreated chemotherapy induced haematological disorder is reported to increase to have a negative effects on prognosis, QOL, and functional/psychological wellbeing in cancer patients. Chemotherapy induced haematological disorders are anaemia, leukopenia, and neutrophillia were found in this study.
\end{abstract}

Keywords: Chemotherapy, Haematology, Adverse drug reaction, Anaemia and Cancer

\section{Introduction}

Cancer is a group of more than hundred diseases that are characterized by uncontrolled cellular growth, local tissue invasion, and distant metastasis. To treat the cancer there are many types of treatments that includes Surgery, Radiation therapy, Chemotherapy. In chemotherapy there are many drugs to treat cancer in that we are conducting a study on effects of the most commonly used chemotherapeutic drugs on haematological parameters of Cisplatin, Paclitaxel. Adverse drug reactions are a global problem adding to the economic burden of the society. Anti-cancer drugs are more prone to cause ADRs and there is lake of pharmacovigilance data on such drugs. Therefore the present study was under taken to monitor haematology related ADRs in the oncology department of a tertiary care teaching hospital in Bangalore. Use of cancer chemotherapeutic drugs is associated with several adverse drug reactions ranging from mild nausea to fatal myelosuppression. Where haematological parameters also play a major role in patient quality of life. Cisplatin, Paclitaxel are the most widely used drugs for cancer therapy in BGS GLOBAL HOSPITAL, BENGALURU. Cancer is the name given to a collection of related diseases. In all types of cancer, some of the body's cells begin to divide without stopping and spread into surrounding tissues. Cancer can start almost anywhere in the human body, which is made up of trillions of cells. Normally, human cells grow and divide to form new cells as the body needs them. When cells grow old or become damaged, they die, and new cells take their place. When cancer develops, however, this orderly process breaks down. As cells become more and more abnormal, old or damaged cells survive when they should die, and new cells form when they are not needed. These extra cells can divide without stopping and may form growths called tumours. Cancerous tumours are malignant, which means they can spread into, or invade, nearby tissues. In addition, as these tumours grow, some cancer cells can break off and travel to distant places in the body through the blood or the lymph system and form new tumours far from the original tumour. Unlike malignant tumours, benign tumours do not spread into, or invade, nearby tissues. Benign tumours can sometimes be quite large, however. When removed, they usually don't grow back, whereas malignant tumours sometimes do. Unlike most benign tumours elsewhere in the body, benign brain tumours can be life threatening ${ }^{2}$.

\section{Methodology}

The study was conducted in the BGS global hospital, Kengeri, Bengaluru. It is a 300 bedded multispecialty tertiary care teaching hospital. This is a retrospective, prospective and observational study and was 
conducted for a period of six months approved by Institutional Ethical Committee of P E S College of pharmacy, Bengaluru.

1.1 Source of data:

All the relevant and necessary data collected from Patient case file,Interviewing patient or patient's care takers,

Health information system (HIS), Medical records department (MRD)

1.2 Inclusive criteria:

i. Patient who are prescribed by these drugs (Cisplatin, Paclitaxel, carboplatin +paclitaxel)

ii. Patients of both Genders.

iii. Patients who are willing to participate and giving their consent.

1.3 Exclusive criteria:

iv. Patients who are not receiving these drugs.

v. Those who are not willing to participate in the study.

1.4 Informed Consent:

Before enrolling the subjects to the study, the patients were informed about all the aspects of the study, nature of the study and purpose of the study. The informed consent forms (Annexure I) were given to the subjects in both English and Kannada, sufficient time was given to the patients to read through all the aspects of the same and all the questions regarding the study were answered by the investigators. The patients, who were interested to participate voluntarily, had to sign the informed consent form and henceforth were enrolled into the study. For those patients who were illiterate, the subject's thumb impression was taken on the informed consent form.

1.5 Designing of Data Collection Form:

vi. Specially designed data collection form (Annexure II) was designed and piloted to collect, document and analyze the data.

vii. The data collection form had provision for collecting key information like demographics (UHID, age, gender, weight), past medical history, present diagnosis,and laboratory investigations, medications their dose and duration, frequency, clinical progress and assessed for adverse drug reactions.

1.6 Computerization of Data Collection and Assessment forms:

The data collection and Assessment form designed for use in this study was computerized using Microsoft Excel 2007 (Annexure III) for easy accessibility, retrieval and analysis of data.

1.7 Study Procedure:

viii. The data collection form and Informed consent form was designed and pilot study conducted to ensure the practical suitability to conduct the study. Once pilot study was done, the data collection form was rectified and the study was started.

ix. Patients meeting the study criteria were enrolled into the study and were followed on daily basis from the day of hospital admission till discharge.

x. Relevant details of these patients such as demographic variables (UHID, age, gender, weight), past medical history, present diagnosis, and laboratory investigations, medications their dose and duration, frequency, clinical progress and assessed for Drug related problems.

xi. The patient's details were collected by using the case sheet or by directly asking the patients, medical records or health information system of the hospital.

xii. All information relevant to the study was collected at the time of admission till the date of discharge and the data will be analysed using suitable method for statistical analysis.

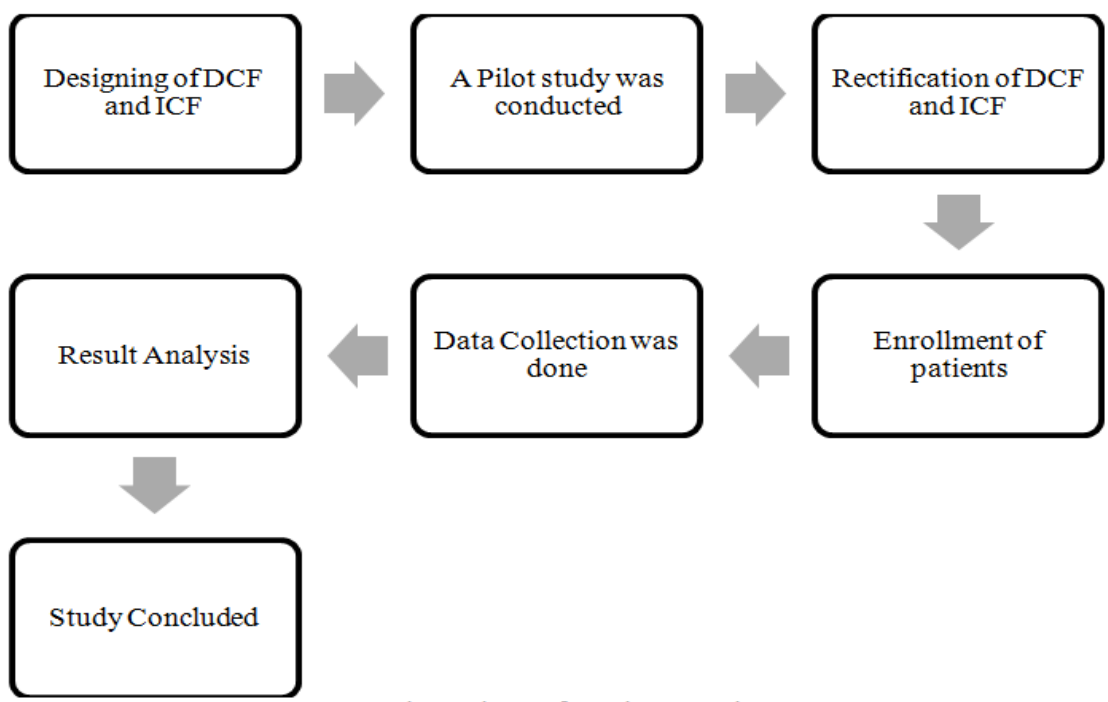

Flow Chart of Study Procedure 
1.8 Source of data collection:

Data will be collected from patient case files from the patients who will be admitted more than 24 hours in the Oncology department or patients who undergoing chemotherapy and chemotherapeutic drug prescription.

1.9 Documentation:-

The data collected from the patients were documented and the result was analyzed.

1.10 Analysis: Microsoft Excel 2007.

\section{Results}

A Prospective observational study was conducted over a period of 6 months in tertiary care hospital in view to assess the effect of chemotherapeutic drugs on haematological parameters. A total number of 93 patients were enrolled in the study. Out of the patient reviewed, 24 (26\%) were male and 69 (74\%) were females.

Table 1: Demographics of study Population

\begin{tabular}{|l|l|}
\hline \multicolumn{1}{|c|}{ Parameter } & \multicolumn{1}{c|}{ Total number of patients } \\
\hline Male & $24(26 \%)$ \\
\hline Female & $69(74 \%)$ \\
\hline Mean age of study population (years) & $53.23 \pm 11.90$ years \\
\hline
\end{tabular}

Out of 93 patients, 46 (49\%) received cisplatin, 25 (27\%) received paclitaxel and 22 (24\%) received combination of paclitaxel and carboplatin for the various cancer treatments.

Table 2: Distribution of subjects according to the drugs used in the chemotherapy

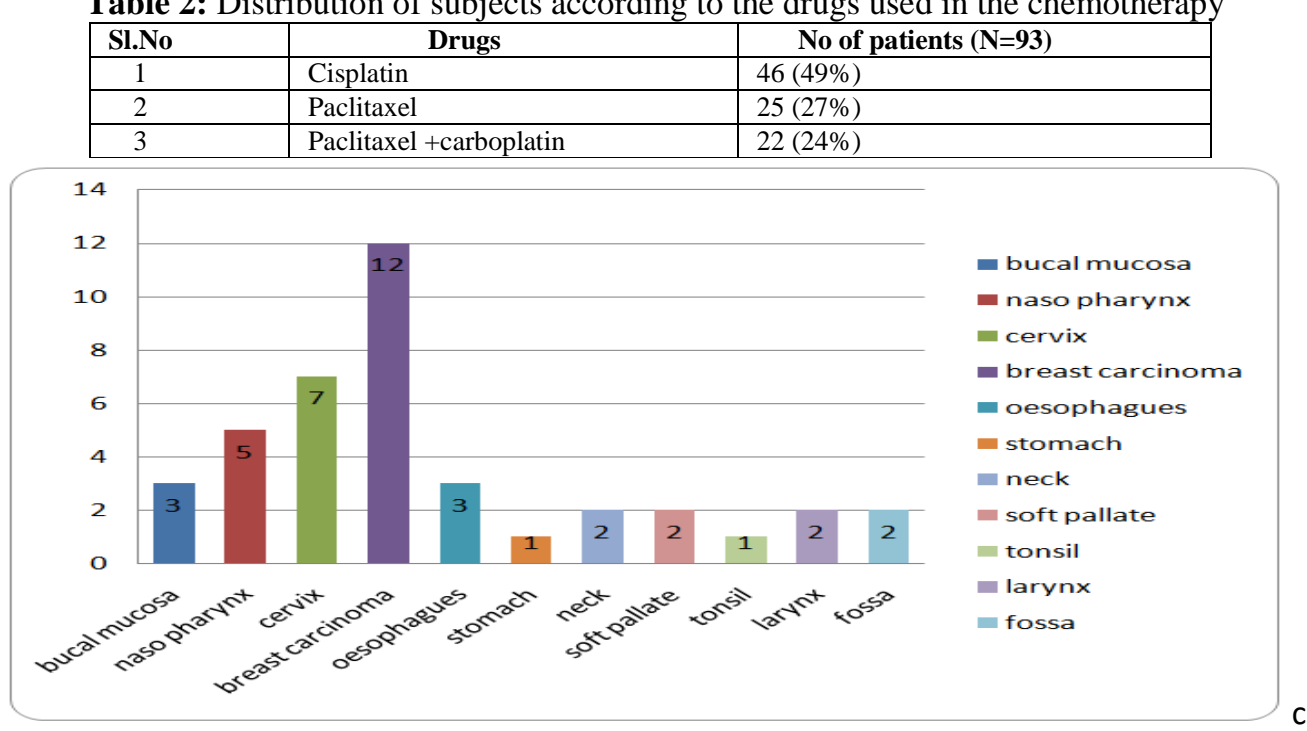

Fig 1: Cisplatin therapy given for different diagnosis

The above data shows the distribution of patients based on use of cisplatin in various types of cancer.

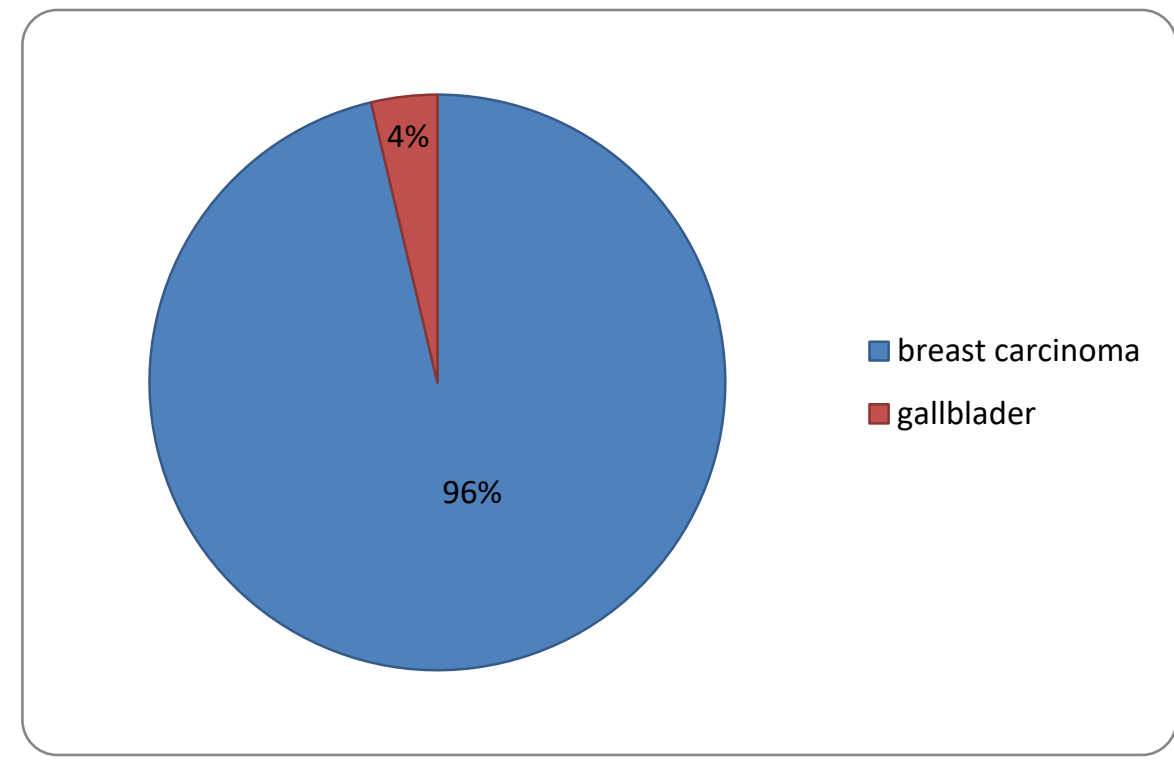

Fig 2: Paclitaxel therapy given for the different diagnosis 
Paclitaxel was used only for breast and gallbladder cancer for our study population.

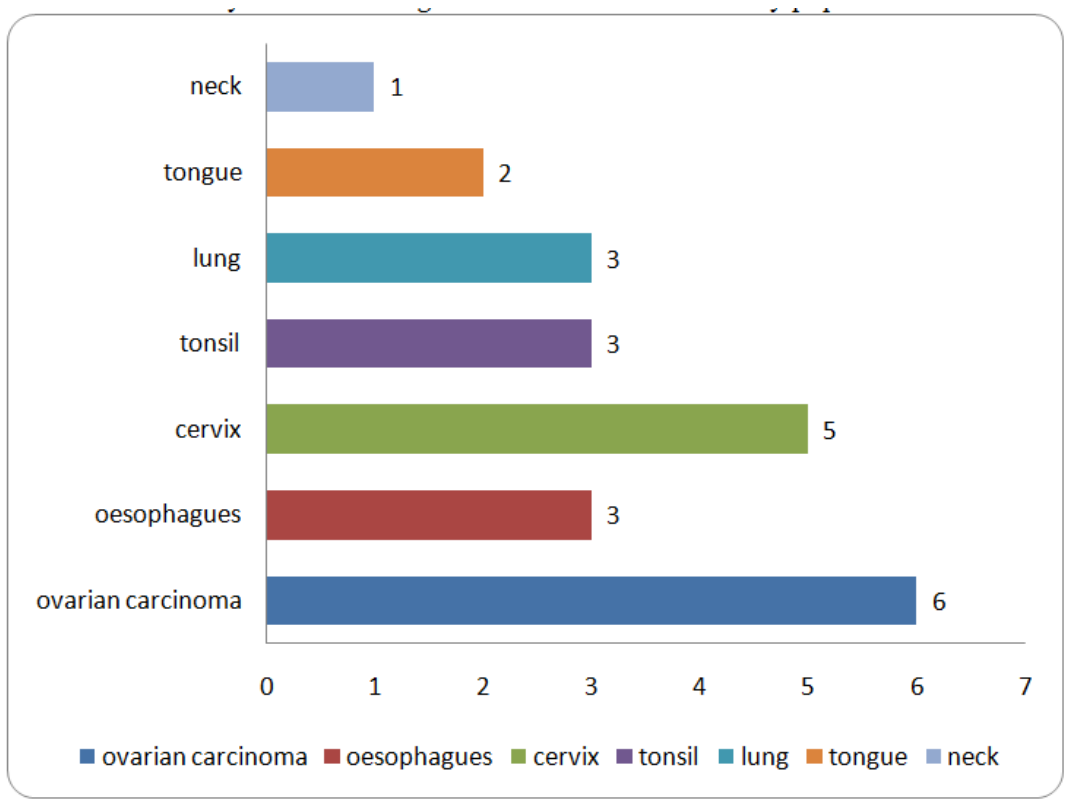

Fig 3: Paclitaxel +carboplatin given for the different diagnosis

Above graph shows the use of paclitaxel and carboplatin combination in various types of cancer for our study.

Total of 46 patients received cisplatin therapy for various types of cancers, out of which 44 patients suffered anemia, 46 leukopenia and 46 neutrophilia as shown in table 3 and figure 4.

Table 3: Effect of cisplatin on haematological parameters

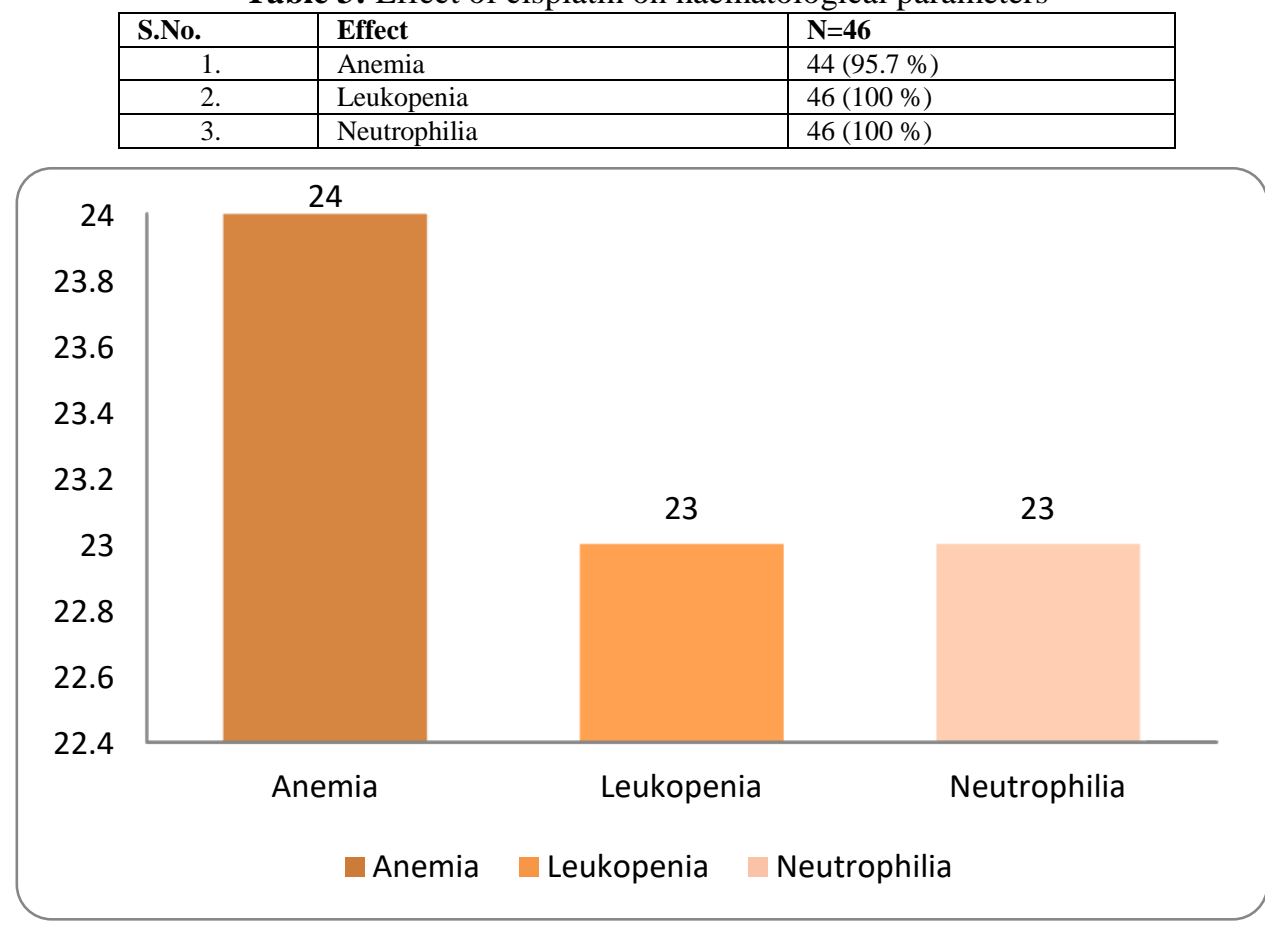

Fig 4: Effect of cisplatin on haematological parameters

Table 4: Effect of paclitaxel on haematological parameters

\begin{tabular}{|c|l|l|}
\hline S.No. & Effect & $\mathbf{N = 2 5}$ \\
\hline 1. & Anemia & $24(96 \%)$ \\
\hline 2. & Leukopenia & $23(92 \%)$ \\
\hline 3. & Neutrophilia & $23(92 \%)$ \\
\hline
\end{tabular}




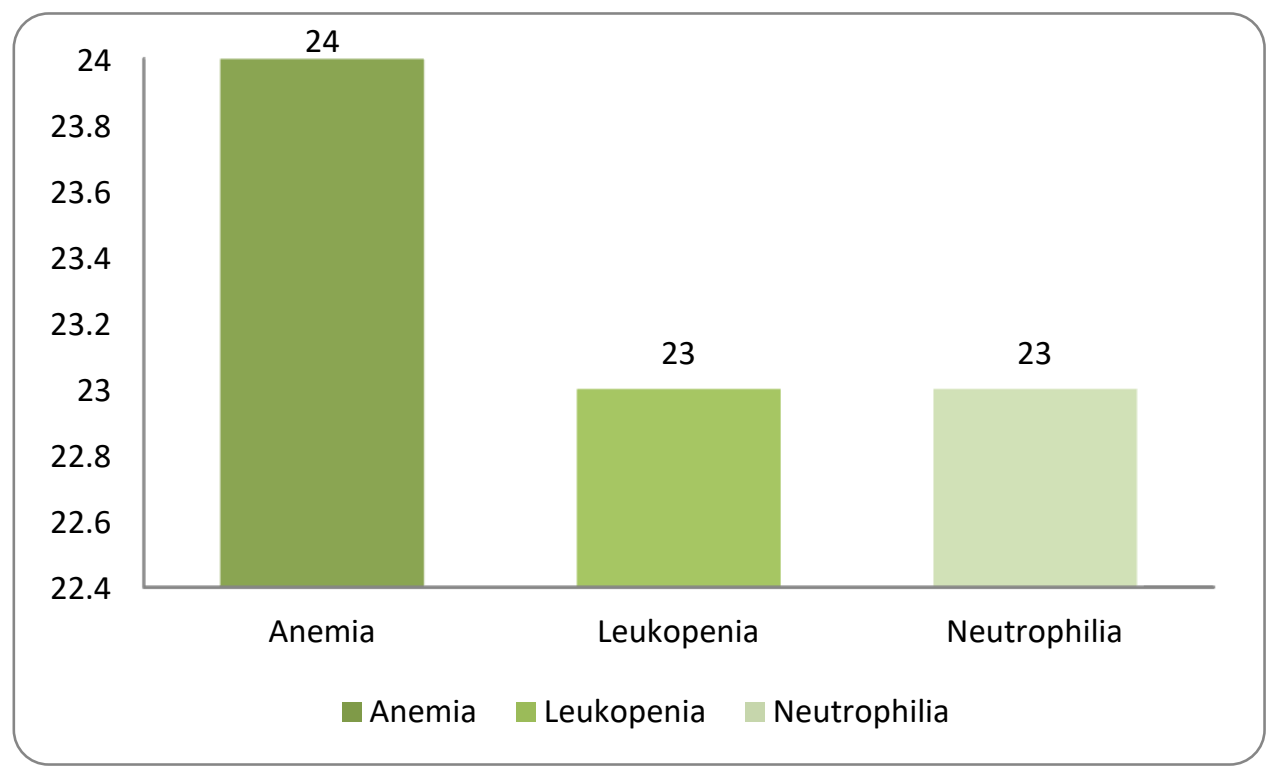

Fig 5: Effect of paclitaxel on haematological parameters

Table 5: Effect of paclitaxel and Carboplatin on haematological parameters

\begin{tabular}{|c|l|l|}
\hline Sl.No. & Effect & $\mathbf{N = 2 2}$ \\
\hline 1. & Anaemia & $22(100 \%)$ \\
\hline 2. & Leukopenia & $21(95.45 \%)$ \\
\hline 3. & Neutrophilia & $22(100 \%)$ \\
\hline
\end{tabular}

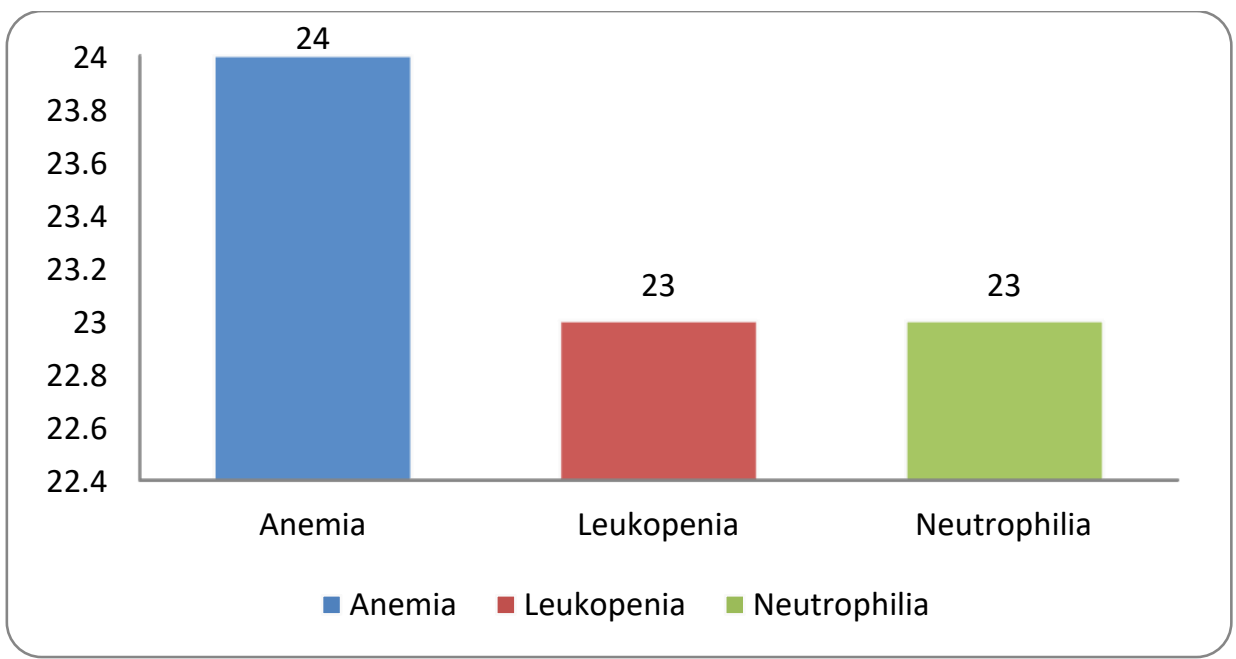

Fig 6: Effect of paclitaxel and Carboplatin on haematological parameters

\section{Discussion}

The main objective of the study is to assess the effects of chemotherapeutic drugs on haematological parameters and to monitor the safety of chemotherapeutic drugs. The total number of 93 was enrolled for the study who was admitted in the chemotherapy ward.Total number of enrolled patients were 93, among those male were $24(26 \%)$ and female were 69 (74\%) which has been represented in table.1 and figure.1 respectively. Out of total number of subjects $46(49 \%)$ were using cisplatin, $25(27 \%)$ were using paclitaxel and $22(24 \%)$ were using paclitaxel+ carboplatin which has been represented in table. 2 and figure. 2 respectively. According to the table3. And figure 3. In total number of patients Out of which $46(49 \%)$ patients using cisplatin $94 \%$ are observed with anaemia where as $100 \%$ are observed with leucopoenia and neutrophillia The study conducted by wood and William j et al showed that all 47 patients completed a total of 365 monthly courses which serve as a data base for this report. A progressive and cumulative anaemia was observed with successive course of cisplatin therapy the onset of this haemoglobin decline was not delayed but was seen after the first course of therapy with continued progressive with the further therapy. Additionally, the greatest decline in blood leucocytes occurred. According to table 4 and figure 4. In total number of patients out of which $25(27 \%)$ patients using paclitaxel $96 \%$ are observed with anaemia where as $92 \%$ were observed with neutropenia and 
leucopoenia. According to table 5 and figure 5 in total number of patients out of which $22(24 \%)$ patients using the combination of carboplatin and paclitaxel $100 \%$ were observed with anaemia and neutrophillia where as 95\% are observed with leucopoenia. A retrospective study conducted by seisuke kumigai et al. Showed similar results that grades 2-4 anaemia was observed in $19.8 \%$ of patients before first line TC. The incidence of grade $3 / 4$ anaemia rapidly increased to $56.1 \%$ after the $4^{\text {th }}$ cycle of TC. Study conducted by C K Lee et al showed that leucopoenia was common toxicity in patients using cp combination chemotherapy. George m et al conducted study on cancer and chemotherapy induced anemia showed that anaemia is prevalent in 30-90\% of patients with cancer. Study conducted by D H Johnson et al showed that among 51 eligible patients there were no complete and partial responses, for an overall response rate of $27 \%$. The median progression- free survival time was 23.8 weeks and median survival time, 38 weeks. The survival rate at year was $32 \%$. Grade three or four granulocytopenia was observed in $47 \%$. Paclitaxel + carboplatin is a moderately active regimen in patients with advanced NSCLC.Joseph A. Sparano et al conducted a study on defining a role and predicting benefit from platinum based therapy in breast cancer showed that was recognised that platinum and that neoadjuvant platinum monotherapy was highly effective in breast cancer.Peter G. Ross et al conducted a study on concurrent cisplatin-based radiotherapy based chemotherapy for locally advanced cervical cancer showed that 192 patients were assigned to receive chemotherapy with cisplatin were observed with higher rates of survival and progression free survival. A study conducted by Joseph A. Sparano et al showed that weekly paclitaxel after standard chemo adjuvant therapy improves disease - free and overall survival in women with breast cancer. A study conducted by George .M Rodgers et al showed that anaemia has come to be viewed as a relatively common condition in patients under chemotherapy. Those receiving mylosuppresive chemotherapy have a higher incidence of $70-90 \%$.

\section{Conclusion}

Chemotherapy induced hematological disorders is a common problem in cancer patients who are treated with the myelosuppression chemotherapy, many patients with chemotherapy induced hematological disorders tend to be under treated clinically. Untreated chemotherapy induced hematological disorder is reported to increase to have a negative effects on prognosis, QOL, and functional/psychological wellbeing in cancer patients. Chemotherapy induced hematological disorders are anemia, leucopenia, and neutrophillia were found in this study.

\section{Limitations}

1. The data collected was irrespective of their chemotherapy cycles.

2. The period of study was six months which was very limited to carryout observations in a wider aspect.

3. There were inconveniences to collect sufficient data since the study was purely observational.

Anticipated Benefits

1. Evaluate Safety of the use of cisplatin, doxorubicin, and paclitaxel in the Indian population.

2. To assess the need for designing prophylactic regimens for the drugs.

3. For the better patient care.

[1] What Is Cancer? - National Cancer Institute.avilable online at

[2] http://www.cancer.gov/about-cancer/what-is-cancer (accessed on 21.4 .2016 , at 2:40pm)

[3] Cisplatin | Cancer Research UK.www.cancerresearchuk.org , ... > Treatment > Cancer drugs http://www.cancerresearchuk.org/about-cancer/cancers-in-general/treatment/cancer-drugs/cisplatin\#general (accessed on 21.04.2016, at 2:50pm).

[4] Paclitaxel (Taxol) | Cancer Research UK.www.cancerresearchuk.org > ... > Treatment > Cancer drugs

[5] http://www.cancerresearchuk.org/about-cancer/cancers-in-general/treatment/cancer-drugs/paclitaxel (accesed on 21.04.2016, at $2: 55 \mathrm{pm})$

[6] Carboplatin medical facts from Drugs.com.www.drugs.com > Drugs A to Z > Carboplatin

[7] http://www.drugs.com/mtm/carboplatin.html (accessed on 21.04.2016, at 3:10pm)

[8] Knight K, Wade S, Balducci L. Prevalence and outcomes of anemia in cancer: a systematic review of the literature. Am J Med 2004;116(Suppl 7A):11S-26S.

[9] Schwartz RN. Anemia in patients with cancer: incidence, causes, impact, management, and use of treatment guidelines and protocols. Am J Health Syst Pharm 2007;64:S5-13; quiz S28-30.

[10] Steensma DP. Is anemia of cancer different from chemotherapy-induced anemia? J ClinOncol 2008;26:1022-1024. 


\section{LIST OF APPENDICES}

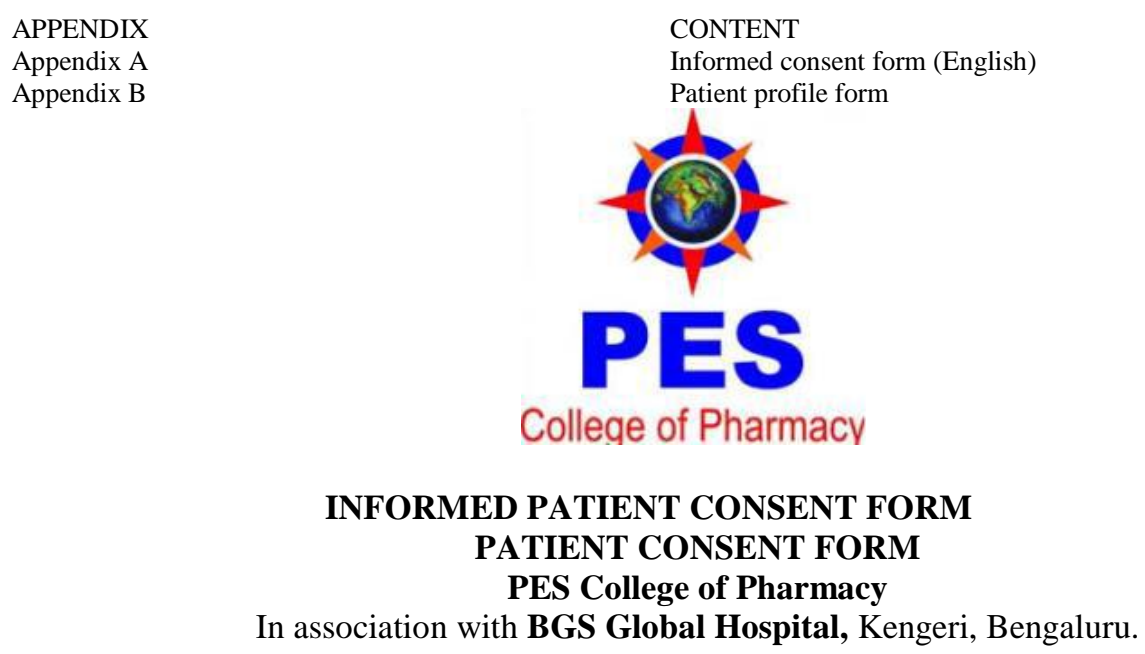

This informed consent form is for patients who on chemotherapy, BGS Global hospital, Kengeri, Bengaluru, for the research titled "A STUDY ON EFFECTS OF THE MOST COMMONLY USED CHEMOTHRAPEUTIC DRUGS ON HAEMATOLOGICAL PARAMETRES (CISPLATIN, PACLITAXEL and CARBOPLATIN+PACLITAXEL)".

This informed consent form has 2 parts:

Part I : Information sheet

Part II : Certificate of consent

You will be given a copy of the Informed consent form

\section{PART I : Information Sheet}

We are students of Doctor of Pharmacy (Pharm.D), studying in PES College of Pharmacy, Bangalore. We are doing a research on EFFECTS OF THE MOST COMMONLY USED CHEMOTHRAPEUTIC DRUGS ON HAEMATOLOGICAL PARAMETRES (CISPLATIN, PACLITAXEL and CARBOPLATIN+PACLITAXEL)". We invite you to be part of our research. You are not required to make a decision about joining our research immediately. The decision to take part or not to take part can be done after proper enquiry and however you feel comfortable.

The consent form may contain words that you may not understand, please bring that to our notice so that we can explain to you what it means. If you have any questions later, you can ask them to me or the co-researcher.

\section{Purpose of the research}

Chemotherapy patients suffering from various haematological disorders.

Our purpose is to find the following-:

- Evaluate Safety of the use of cisplatin, doxorubicin, and paclitaxel in the Indian population.

- To assess the need for designing prophylactic regimens for the drugs.

For the better patient care

Type of research intervention:

This research will involve you to participation of around 15 minutes interview.

\section{Participation selection:}

You are being invited to take part in this research because we feel that your experience as a responsible citizen, who can contribute much to our understanding and knowledge of local health practice.

\section{Procedures:}

The case collection was done through accurately and precisely designed form (Patient profile form). This was designed in such a way that it includes all the necessary information with regards to study like demographic details, past medical history, present diagnosis, laboratory investigation, medications their dose and duration, frequency, clinical progress and assessed for Drug related problems. Adverse drug reaction reporting form will be designed to collect the data regarding ADRs. One separate questionnaire regarding 
sociodemographic characteristics will be developed and used in the study. To assess the Scale and WHO scales will be used.

\section{Duration:}

The research takes place over 6 months in total, during this time the feed-back given by you and the follow up will be carried out. Each interview will last for about 15 minutes.

\section{Risk:}

No risk of participation, sharing of your confidential information and change in current medications. The study does not interrupt your chemotherapy treatment.

\section{Benefits:}

The benefits to you and your participation in this study will help us find out more about drug related problems, patient care and better quality of life.

\section{Reimbursements:}

You will not be provided any incentive to take part in the research

Confidentiality:

We will not be sharing information about you to anyone outside the research team. The information that we collect from our research project will be kept private. Any information about you will have a number on it instead of your name, only the researcher will know what your identity. It will not be shared with or given to anyone except us

$\square$ I have been given enough information about this project

It has been explained to me how the information I gave will be used

$\square$ I agree to talk to the researcher about my experience of getting support

I give permission for the researcher to speak to my support worker

I understand that I can leave the research at any time and do not have to answer all the questions if I don't want to

$\square$ I give permission for my words to be used in a report, understanding that my name will not be mentioned

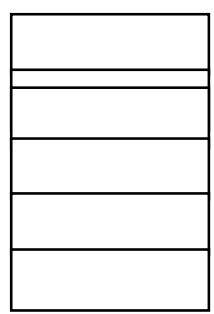

\section{CERTIFICATE OF CONSENT (mandatory)}

I have read the foregoing information, or it has been read to me. I have had the opportunity to ask questions about it and any question I have been asked have answered to my satisfaction. I consentingly volunteer to be a participant in this study.

Name of Participants:

Signature of Participants:

Date: - Month Year

\section{If Illiterate,}

I have witnessed the accurate reading of the consent form to the potential participant, and the individual has had the opportunity to ask questions. I confirm that the individual has given consent freely.

Name of witness:

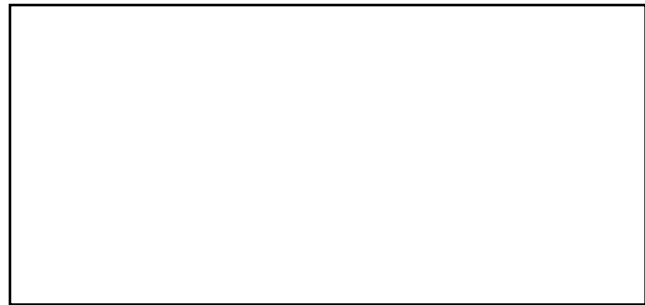

Thumb

impression/signature of participant:

Signature of witness:

Date : $/$ I $/$ Y $/$

\section{Statement by the researcher / person taking consent}


I have accurately read out the information sheet to the potential participant to the best of my ability and made sure that the participant understands that following will be done:

1.

2.

I confirm that the participant was given an opportunity to ask questions about the study, and all the questions asked by the participant have been answered correctly to the best of my ability. I confirm that the individual has not been compelled into giving consent, and the consent have been given freely and voluntarily

The copy of this ICF has been provided to the participant.

Name of the Researcher/person taking consent:

Signature of the Researcher/person taking consent:

Date :

\section{Department of Pharmacy Practice}

BGS Global Hospitals

In associate with

PES college of Pharmacy

College of Pharmacy

Doctor of Pharmacy (Pharm.D)

Name:

Serial No:

Date:

PATIENT DATA COLLECTION FORM

Demographics:

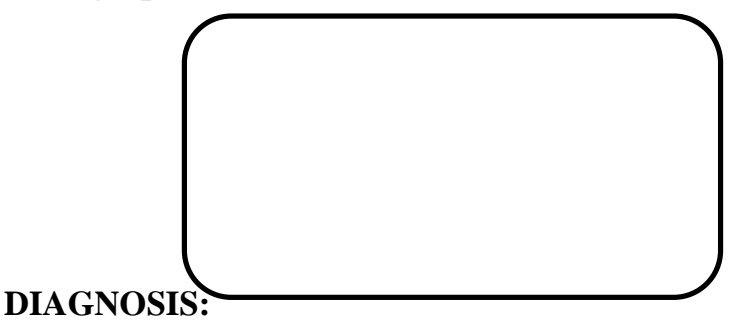

\begin{tabular}{|c|l|}
\hline Admission Date & \\
\hline Discharge Date & \\
\hline Weight & \\
\hline Height & \\
\hline BMI & \\
\hline
\end{tabular}

\section{DIAGNOSIS}

\section{CYCLE:}

\section{PAST MEDICATION HISTORY:}

GASTROINTESTINAL:

LABORATORY INVESTIGATION

\begin{tabular}{|l|l|l|l|l|l|l|l|}
\hline & & & & & & & \\
\hline Nausea & & & & & & & \\
\hline Vomiting & & & & & & & \\
\hline Diarrhoea & & & & & & & \\
\hline IDMM & & & & & & & \\
\hline Stomatitis & & & & & & & \\
\hline
\end{tabular}


HEMATOLOGY:

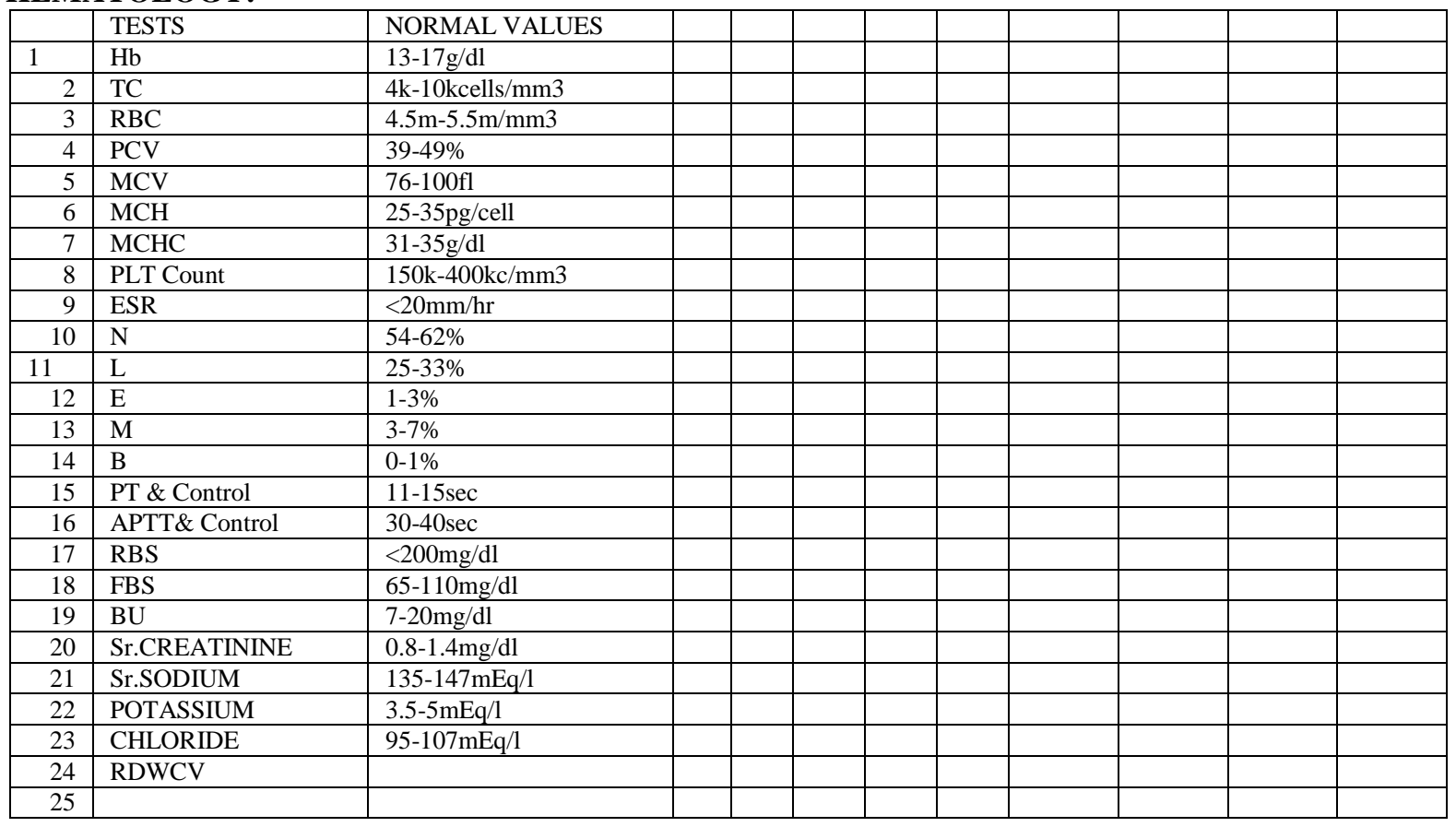

IOSR Journal of Pharmacy and Biological Sciences (IOSR-JPBS) is UGC approved Journal with Sl. No. 5012, Journal no. 49063.

PV.Akshaya. "A Study On Effects Of The Most Commonly Used Chemotherapeutic Drugs On Haematological Parametres." IOSR Journal of Pharmacy and Biological Sciences (IOSR-JPBS) 12.4 (2017): 01-10. 